\title{
Utilization of morcellation during laparoscopic surgery of uterine fibroid: yes or not?
}

\author{
Balkenzhe Imankulova ${ }^{1}$, Talshyn Ukubassova ${ }^{1}$
}

${ }^{1}$ Women's Health Unit, National Science Center for Maternity and Childh Health

CF "University Medical Center", Astana, Kazakhstan

This work is licensed under a

Creative Commons Attribution 4.0

International License

\section{J Clin Med Kaz 2017; 3(45 Supp/ 3):25-28}

Автор для корреспонденции: Иманкулова Балкенже Жаркемовна, врач акушер-гинеколог высшей категории, к.м.н., отделение женских болезней, Национальный научный центр материнства и детства, КФ «University Medical Center», г. Астана, улица Турана 32, с.т. 87013504322 , р.т 701443 (вн. 1606), imanbalken@mail.ru
Abstract

Objective. The study of the need for a differentiated approach to morphology during laparoscopic myomectomy and hysterectomy, for the prevention of the spread of an undiagnosed malignant process

Methods. The retrospective analysis 134 operations of a myomektomiya and a hysterectomy which are carried out in National scientific center of Maternity and the Child Health in 2014 and 2015, where in one case the high-differentiated adenocarcinoma is noted after a laparotomy aproch total hysterectomy with ovarium and tubs is carried out.

Results. Recommendations are given for conducting a total hysterectomy and extraction of the uterus through the vagina and use of endobago during the fermentation of myomatous nodes to prevent the spread of malignant processes.

Conclusion. It is advisable to support the recommendations of the American Collegium of Obstetricians and Gynecologists, the European Society for Gynecological Endoscopy and the American Society of Gynecological Laparoscopy on the oncologic alertness of using a morphator during laparoscopic surgery for uterine myomas.

Key words: uterine fibroid- hysterectomy-myomectomy -morcelator

\section{ТҰЖЫРЫМДАМА}

\section{ЖАТЫР МИОМАСЫНДА ЛАПАРОСКОПИЯЛЫК ОПЕРАЦИЯ КЕЗІНДЕ МОРЦЕЛЛАТОРДЫ КОЛДАНАСЫЗ БА: ИӘ} НЕМЕСЕ ЖОК?

Иманқұлова Б.Ж. ${ }^{1}$, Үкібасова Т.М.'

'Әйелдер аурулары бөлімшесі, Ана мен бала ұлттық ғылыми орталығы

"University Medical Center " ҚҚ, Астана, Қазақстан

Мақсаты. The study of the need for a differentiated approach to morphology during laparoscopic myomectomy and hysterectomy, for the prevention of the spread of an undiagnosed malignant process.

Зерттеудің әдістері. Ұлттық ана мен бала ғылыми орталығында 2014 және 2015 жылдардың арасында жасалған 134 отаның миомэктомия және гистерэктомия ретроспективті талдау жүргізілген.

Нәтижелері. Recommendations are given for conducting a total hysterectomy and extraction of the uterus through the vagina and use of endobago during the fermentation of myomatous nodes to prevent the spread of malignant processes.

Қорытынды. Бір жағдайда лапаротомдық жалпы гистерэктомиядан кейін аденокарцинома анықталған. Гистерэктомия жасағанда жатырды қынап арқылы шығаруды және миоматоздық түйынділерді морцеляция кезінде эндобагты пайдалану кажеттылыгы катерлі ісіктерді таралуының алдын алу туралы жалпы ұсыныстар берілген.

Маңызды сөздер: жатыр миомасы- гистерэктомия- миомэктомия- морцелятор

\section{PEЗЮME}

\section{ИСПОЛЬЗОВАТЬ МОРЦЕЛЛЯТОР ВО ВРЕМЯ ЛАПАРОСКОПИЧЕСКОЙ ОПЕРАЦИИ ПРИ МИОМЕ МАТКИ: ДА}

\section{ИЛИ НЕТ?}

Иманкулова Б.Ж. ${ }^{1}$, Укыбасова Т. М. ${ }^{1}$

'Отделение женских болезней, Национальный научный центр материнства и детства

КФ"University Medical Center", г. Астана, Казахстан

Цель исследования. Изучение необходимостидифференцированного подхода морцеляции во время лапароскопической миомэктомии и гистерэктомии, для профилактики распространения не диагностированного злокачественного процесса

Методы. Проведен ретроспективный анализ 134 операции миомэктомии и гистерэктомии, проведенных в Национальном научном центре материнства и детства в 2014 и 2015 годах, где в одном случае отмечена после лапаротомной тотальной гистерэктомии с придатками высокодиференцированная аденокарцинома.

Результаты. Даны рекомендации о проведении тотальной гистерэктомии и извлечение матки через влагалище и использование 
эндобаговов во время морцеляции миоматозных узлов для профилактики распространения злокачественных процессов.

Выводы. Целесообразноподдержатьрекомендации Американской коллегии акушеров и гинекологов, Европейского общества по гинекологической эндоскопии и Американского общества по гинекологической лапароскопии о онкологической насторожности использования морцелятора во время лапароскопических операции по поводу миом матки.

Ключевые слова: миома матки - гистерэктомия - миомэктомия- морцелятор

\section{Введение}

Проблема миомы матки является актуальной до сегодняшнего времени вследствие высокой частоты заболеваемости и хирургических вмешательств, встречающиеся у 70-80\% женщин[1]. Распространенность увеличивается с возрастом, достигаямаксимума у 40-летних женщин. Поэтому миома матки-наиболеераспространенное показание к гистерэктомииво всем мире. В Канаде они являются показанием $30 \%$ и второй по частоте гинекологической операцией в области акушерства и гинекологии после кесарева сечения[2]. В России 90\% гистерэктомий в репродуктивном возрасте проводится по поводу доброкачественных новообразований матки [3]. В Казахстане нет статистики по частоте гистерэктомии. В Национальном научном центре материнстве и детства с внедрением эмболизации маточных артерий гистерэктомия составляет около $25 \%$ от всех гинекологических операции по поводу миомы матки.

В отличиеот миомы матки леймиосаркома матки развиваются очень редко: она составляет менее $1 \%$ всех малигном в теле матки, их зарегистрированная частота составляет 0,64 на 100000 женщин в год [3].

Первоесообщениеогистерэктомиилапароскопическим доступом принадлежит Х. Рич (1989). В 1991 г. К. Земм описал эндоскопически произведённую гистерэктомию без кольпотомии. Сразу же после этих публикаций лапароскопическую гистерэктомию стали проводить в тех ведущих клиниках США, Европы и Австралии, где использовался эндоскопический доступ (Лу, 1994; Д. Мейдж и соавт., 1992; Х. Рич, 1992; Дж. Филлипс и соавт., 1993, и др.[4].В Казахстане лапароскопическим доступом в $90-\mathrm{x}$ годах проводили миомэктомию, а в 1999 году проведена первая гистерэктомия по поводу миомы матки.

Определённым препятствием для расширения показаний к гистерэктомии и миомэктомии лапароскопическим доступом была и остается величина удаляемого объектаиз - за ограничения пространства для манипуляции и пути эвакуации. Поиск решения этой проблемы привел к разработке метода морцеляции измельчение ткани в длинные полосы, что дает возможность извлечения из брюшной полости через лапароскопическ ие порты менее 2см. И с 1993 года в мире применяется морцеляция миоматозных узлов, матки после субтотальной гистерэктомии. Отрицательными моментами является то, что во время морцелляции ткань опухоли или матка разделяется на мелкие кусочки и если ранее появились сведения о развитии морцелом брюшной и тазовой полости, то сейчас появились данные о распространенности малигнизации процессов матки в брюшную полость.
Значительное измельчение клеток опухоли во время морцеляции может привести к распространению заболевания на всю брюшную полость. Морцелляция также может привести к диссеминации лейоматозной ткани (лейомиоматоз) и клеток лейомиосаркомы [4-12].

Целью исследования было выяснить был ли диагностирован злокачественный процесс на гистологическом исследовании при проведении операции по поводу миомы матки с использованием морцелятора и без морцелятора.

\section{Материал и методы}

Нами проведена ретроспективная оценка результатов гистологического исследования удаленных опухолей и состояния здоровья пациентов, которые прооперированы в 2014-2015 годах по поводу миомы матки, у которых во время операции применяли морцелятор или интраперитонеальное рассечение тканей миомы или миоматозной матки.

\section{Результаты}

Средний возраст пациенток составил $41,0 \pm 0,5$ лет. Показаниями к операции по поводу миомы матки были боли внизу живота и пояснице, обильные менструации, сдавление соседних органов.

Показаниями для операции явились в $65 \%$ миома матки, в 25\% сочетание миомы матки с аденомиозом, в 9,3\% миома матки и гиперплазия эндометрия в сочетании с полипом эндометрия, в 0,74\% генитальный пролапс с целью промонтофиксации шейки матки.

Диагностическое выскабливание полости матки до операции имели всего 7 пациенток. Результатом гистологического исследования при диагностических выскабливаниях полости матки были железистая гиперплазия эндометрия и железисто - фиброзный полип эндометрия. Гормональное лечение получала лишь одна пациентка, препарат Эсмия в течение 3-х месяцев с целью предоперационной подготовки на консервативную миомэктомию.

В анамнезе отмечены предшествующие операции: аппендэктомия - 26, эмболизация маточных артерий 2 , тубэктомия - 9, холецистэктомия - 3, фиброаденома молочной железы - 2, мастэктомия -1, гистерорезектосопия - 4, вылущивание миоматозного узла -1, цистэктомия -3, кесарево сечение - 4, протезирование митрального клапана -1 , секторальная резекция молочной железы -1, резекция яичника - 1, консервативная миомэктомия - 4, диагностическая лапароскопия - 5, склеропластика -1, полипэктомия эндометрия - 4, удаление паховой грыжи -1, пупочной грыжи -1, грыжа дисков позвоночника -1 .

Из таблицы видно, что наиболее часто миома матки

Таблица 1 Возраст пациентов, оперированных по поводу миомы матки

\begin{tabular}{|c|c|c|}
\hline Годы & Частота & Процент \\
\hline $20-29$ & 9 & $6,7 \%$ \\
\hline $30-39$ & 56 & $41,8 \%$ \\
\hline $40-49$ & 48 & $35,8 \%$ \\
\hline 50-59 & 20 & $15,0 \%$ \\
\hline 60 и старше & 1 & $0,71 \%$ \\
\hline Всего & 134 & 100 \\
\hline
\end{tabular}


встречается в возрасте 30-49 лет. В этом возрасте, учитывая на сегодняшний день позднее планирование беременности, многие пациентки хотят провести консервативную миомэктомию, сохранив репродуктивную функцию.

Проведены операции:у 51,6\% пациенток консерватиная миомэктомия лапароскопическим и лапаротомным доступом, у 35,8\% - гистерэктомия лапароскопическим и лапаротомным доступом и в $12,6 \%$ - вагинальная гистерэктомия и гистерорезектоскопия по поводу субмукозных узлов.

Таблица 2 Виды операции при миоме матки

\begin{tabular}{|l|l|l|l|}
\hline$№$ & Вид операции & & \\
\hline & Количество & Процент & \\
\hline 1 & Вагинальная гистерэктомия & 3 & $2,2 \%$ \\
\hline 2 & Гистерорезектоскопическая миомэктомия & 14 & $10.4 \%$ \\
\hline 3 & Консервативная миомэктомия лапароскопическая & 29 & $21,7 \%$ \\
\hline 4 & Консервативная миомэктомия лапаротомная & 40 & $29,9 \%$ \\
\hline 5 & Гистеэрэктомия лапароскопическая & 18 & $13,4 \%$ \\
\hline 6 & Гистерэктомия лапаротомная & 30 & $22,4 \%$ \\
\hline & Всего & 134 & $100 \%$ \\
\hline
\end{tabular}

Морцеллятор был использован в 22 случаях (16,4\%) и в 53 случаях $(39,5 \%)$ извлекали удаленный орган или миоматозные узлы путем рассечения.

Прианализерезультатовгистологическихисследований удаленных тканей матки показал, что только в одном случае отмечена выскодифферецированная аденокарцинома у пациентки 83 лет,которой была проведена тотальная гистерэктомия с придатками лапаротомным доступом. Пациентка осмотрена онкогинекологом до операции и рекомендовано оперативное лечение в гинекологии общего профиля. Во всех остальных случаях результатом гистологического исследования былилейомиома матки, все пациенты благополучно выписаны на 3-5-7 сутки после операции.

Осложнения отмечены в 2 случаях:кишечная непроходимость, пациентка переведена в хирургическое отделение на 7 сутки после консервативной миомэктомии лапаротомным путем. Данная пациентка принимала препарат Эсмия с предоперационной подготовкой для снижения объема миоматозных узлов. Матка была размером 160x150ммперед операцией. И один случай релапаротомии по поводу кровотечения после тотальной гистерэктомии. Кровопотеря составила 800мл. Произведена ревизия и ушивание влагалищных ветвей артерии.

Таким образом, в данном ретроспективном анализе отмечен $\quad 0,7 \%$ случай высокодифференцированной аденокарциномы после операции по поводу миом матки.

\section{Обсуждение}

Научные сотрудники Колледжа врачей и хирургов Колумбийского университета (Columbia University College of Physicians and Surgeons, Нью-Йорк, штат Нью-Йорк, США) провели исследование с участием 36470 женщин, перенесших минимально инвазивную гистерэктомию с морцелляцией матки в период между 2006 и 2012 гг. в более чем 500 больницах страны. Целью было выявление рака тела матки (все результаты гистологических исследований) на основе Международной классификации болезней. Исследователи изучили возникновение новообразований матки, злокачественных новообразований других частей матки, в том числе рака шейки матки и прилегающих придаточных структур (другой гинекологический рак) и гиперплазии эндометрия.

Результаты показали, что среди тех, кто прошел морцелляцию, были определены 99 случаев рака матки, что составило 0,27\%. Обнаружено 26 случаев других гинекологических злокачественных опухолей и 39 маточных новообразований неопределенного злокачественного потенциала, что составило $0,1 \%$ и 368 (1,0\%) случаев гиперплазии эндометрия. Среди женщин, которые подверглись морцелляции, пожилой возраст был связан со скрытым раком и гиперплазией эндометрия. Соотношение распространенности злокачественного процесса матки увеличилось в 4 раза: с 4,97 у женщин в возрасте от 5054 лет до 19,37 в возрастной группе от 55-59 лет, до 21,36 в возрастной группе 60- 64 лет, до 35,97 для женщин в возрасте 65 лет и старше [5].

Учитывая, что в мире уже появились публикации об опасности морцеляции матки и миоматозных узлов во время лапароскопической операции необходимо задуматься о безопасности пациентов после операции. Необходимо рассмотреть альтернативные варианты оперативного лечения для женщин с симптоматическими миомами матки, которые не требуют электрической морцелляции. Можно рекомендовать закрытую морцелляцию в контейнере как способ уменьшить риск случайной диссеминации малигнизированныхтканей матки. Информировать пациенток о том, что лапароскопическая морцелляция матки во время миомэктомии может способствовать распространению случайно недиагностированной саркомы и ухудшить прогноз для жизни.

На последнем конгрессе Европейского общества по гинекологической эндоскопии (ESGE) в октябре 2016 года в Брюсселе были даны рекомендации о необходимости использования эндобагов и морцеляцию проводить в эндобаге. Согласно этим рекомендациям, гинекологи должны проводить тщательное предоперационное обследование, чтобы исключить возможное злокачественное перерождение опухоли и соответственно информировать пациенток о возможных рисках, связанных с удалением опухоли с применением метода морцелляции. Необходимо обследовать на онкомаркеры и консультировать онкогинекологом. Обязательным является диагностическое выскабливание полости матки перед гистерэктомией. Проводить консультации с пациентками о необходимости тотальной гистерэктомии и по возможности извлечение матки вагинальным путем или проводить мини разрезы на передней брюшной стенке и излечение миом матки и матки в эндобаге. 
Выводы

Целе с ообразно поддержать рекомендации Американской коллегии акушеров и гинекологов, Европейского общества по гинекологической эндоскопии и Американского общества по гинекологической лапароскопии о онкологической насторожности использования морцелятора во время лапароскопических операции по поводу миом матки.

\section{Литература}

1. Baird, D.D., Dunson, D.B., Hill, M.C., Cousins, D., Schectman, J.M.High cumulative incidence of uterine leiomyoma in black and white women: ultrasound evidence. J Obstet Gynecol. 2003;188: 100-107.

2. Health Canada.Laparoscopic electric morcellators - risk of spread of unsuspected uterine sarcoma - notice to hospitals. Ottawa. Health Canada; 2014.

3. Tikhomirov A.L., Manukhina E.I., VuchenovichYu.D., Kazenashev V.V., Bgazhnokova M.V. Miomamatkidifferentsirovannyil echebnyipodkhod (Uterine fibroids differentiated treatment approach). Moskva; 2015.84

4. Savel'eva G.M. Laparoskopiya v ginekologii (Laparoscopy in gynecology). Moskva: GEOTAR Meditsina; 1999.

5. Hampton T. Critics of Fibroid Removal Procedure Question Risks it May Pose for Women with Undetected Uterine Cancer. Journal of the American Medical Association (JAMA) 2014; 311( 9): 891-893.

6. Milad, M., Milad E.L aparoscopic morcellator-related complications. J minim Invas Gynecol. 2014;21: 486-491.

7. Sizzi, O., Rossetti, A., Malzoni, M., Minelli, L.Italian multicenter study on complications of laparoscopic myomectomy. J minim Invasive Gynecol, 2007; 14: 453-462.

8. Cucinella, G., Granese, R., Calagna, G., Somigliana, E., Perino.Parasitic myomas after laparoscopic surgery: an emerging complication in the use of morcellator? description of four cases. FertilSteril. 2011; 96: 90-96.

9. Ordulu, Z., Dal Cin, P., Chong, W.W.S., Choy, K.W.Disseminated peritoneal leiomyomatosis after laparoscopic supracervical hysterectomy with characteristic molecular cytogenetic findings of uterine leiomyoma.Genes chromosomes cancer, 2010;49: $1152-1160$.

10. Sinha, R., Sundaram, M., Mahajan, C., Sambhus, A.Multiple leiomyomas after laparoscopic hysterectomy: report of two cases. J minim Invasive Gynecol, 2007;14: 123-127.

11. Sinha, R., Sundaram, M., Lakhotia, S.Recurrentleiomyomatosis.J minim Invas Gynecol. 2009; 16: 668.

12. Ribic-Pucelj, M., Cvjeticanin, B., Salamun, V.Leiomyomatosisperitonealisdisseminata as a possible result of laparoscopic myomectomy - report of four cases. Gynecol Surg. 2013;10: 253-256.

13. 26(9):2513-2517.

14. D’adomo, PJ. Eat Right For Your Type. Putnam Adult. (1997-01-06). ISBN 978-0399142550.

15. Cusack L, De buck E, Compernolle V, Vandekerckhove P. Blood typedietslacksupportingevidence: a systematicreview. Am $J$ ClinNutr. 2013; 98(1):99-104.

16. Mitra R, Mishra N, Rath GP. Blood groups systems. Indian J Anaesth. 2014; 58(5):524-528.

17. Rossi A, DI Lollo AC, Guzzo MP, Giacomelli C, Atzeni , Bazzichi, et al. Fibromyalgia and nutrition: what news?. Clin Exp Rheumatol. 2015; 33(1;88):117-125

18. Arranz LI, Canela MA, Rafecas M. Fibromyalgia and nutrition, what do we know?. Rheumatol Int. 2010; 30(11):1417-1427

19. Buskila D, Neumann L. Genetics of fibromyalgia. Curr Pain Headache Rep. 2005; 9(5):313-315. 